\title{
The effects of economic crises on tourism success: an integrated model
}

\author{
José Francisco Perles-Ribes, Ana Belén Ramón-Rodríguez, Martín \\ SEVILLA-JIMÉNEZ AND ANTONIO RUBIA
}

Department of Applied Economic Analysis (first three authors) and Department of Financial Economics and Accounting (fourth author), Faculty of Economics and Business Sciences, University of Alicante, Campus San Vicente del Raspeig, 03080 Alicante, Spain. E-mail: jose.perles@ua.es. (Corresponding author: José Francisco Perles-Ribes.)

\begin{abstract}
This paper provides a theoretical model of the influence of economic crises on tourism destination performance. It discusses the temporary and permanent effects of economic crises on the global market shares of tourism destinations through a series of potential transmission mechanisms based on the main economic competitiveness determinants identified in the literature. The proposed model explains the non-neutrality of economic shocks in tourism competitiveness. The model is tested on Spain's tourism industry, which is among the leaders of the global tourism sector, for the period 1970-2013 using non-linear econometric techniques. The empirical analysis confirms that the proposed model is appropriate for explaining the changes in the market positions caused by the economic crises.
\end{abstract}

Keywords: economic crisis; destination competitiveness; permanent shocks; economic transmission mechanisms; switching regression models

Crises and their management constitute a popular topic for tourism researchers, and many studies on the characteristics of crises and the actions taken to overcome them have been conducted (Henderson, 1999). The advent of the latest global economic and financial crisis (GFC) has encouraged the proliferation of new articles on this topic, but until now the literature exploring the impact of economic crises on tourism has been quite fragmented. The vastness and complexity of the tourism industry leads authors to focus on either demand (for example, Bhattacharya and Narayan, 2005; Narayan, 2011) or supply aspects (for example, Alonso and Bremser, 2013), but few studies have addressed the effects of crises on destinations from a global perspective or using a

The authors wish to thank the journal's referees for very helpful comments and suggestions. Also the authors wish to thank Professor Bruce E. Hansen (University of Wisconsin-Madison) for providing his code and clarifying some technical questions about our estimations. Financial support from project ECO2011-29751 is acknowledged. 
competitiveness approach. The controversy that still surrounds the concept of tourism competitiveness and the exogenous character of shocks in most theoretical competitiveness models could explain this scarcity of studies linking tourism competitiveness and economic crises.

However, the relationship between economic crises and tourism competitiveness is a very promising field of research, and two papers by Perles and Ramón (2013a) and Perles et al (2013) have recently attempted to fill this gap in the existing literature, thereby opening a debate on this subject. Perles et al (2013) analysed the long-term implications of economic crises for Spain's tourism performance, using market share as a proxy for competitiveness and the unit root test to determine the persistence of the effects of economic crises on tourism destinations. The authors concluded that studies undertaken from a competitiveness perspective enrich analysis based solely on a demand interpretation. Meanwhile, using vector autoregression (VAR) techniques and the Granger causality approach, Perles and Ramón (2013b) explored the differential effects that economic crises generated in tourism destinations, depending of the destinations' mature or emerging status.

Our paper goes beyond attempting to strengthen the theoretical foundations of this new approach by proposing an integrated model that describes the relationships between economic crises, tourism competitiveness and destinations' market performances and by presenting the economic mechanisms operating in this context. An empirical application of this model using non-linear econometric techniques confirms its validity for the Spanish case during the period 1970-2013.

The paper proceeds as follows. The second section reviews the existing literature on economic crises and tourism destination competitiveness. The third section proposes a theoretical model to link the economic crises and tourism success and details the transmission mechanisms operating in this context. The fourth performs the empirical analysis of the model for the Spanish case. Finally, the conclusions and the limitations of the model are presented.

\section{Theoretical background}

\section{Economic crises and international tourism: a literature review}

The United States Business Cycle Dating Committee of the National Bureau of Economic Research (NBER) defines an economic recession as 'a significant decline in economic activity spreading across the economy, lasting more than a few months, normally visible in real gross domestic product (GDP), real income, employment, industrial production and wholesale-retail sales'. ${ }^{1}$ Almost universally, researchers have referred to calculations made by the NBER for the precise dating of a recession's onset and end (Perles et al, 2013). Five crises (Table 1) have been registered by the NBER between 1970 and 2010 for the US economy. Most of these crises have had worldwide effects, becoming global crises that have affected tourist destinations around the globe.

Perles et al (2013) reviewed the existing literature on economic crises and tourism, dividing studies between those that focused on aspects of demand, those that analysed the reactions of industry and those that researched the 
Table 1. Periods of crisis and economic expansion in the US economy.

Observations

First oil crisis.

According to the NBER, the crisis began in November 1973 and ended in March 1975. In Spain, inter-quarterly falls of GDP occurred during the first and second quarters of 1975.

Second oil crisis.

The NBER registered a brief recession lasting 6 months in 1980 and another between July 1981 and November 1982. In Spain, inter-quarterly falls of GDP occurred during the second half of 1978 and the first half of 1979. This period also considers the coup d'état during the first quarter of 1981 with a fall in GDP.

First Gulf War.

The NBER registered a brief recession lasting 8 months between July 1990 and March 1991. In Spain, inter-quarterly falls in GDP occurred during the whole of 1992 and the first quarter of 1993.

Dot.com crisis and 9/11. The NBER registered a brief recession lasting 8 months between March 2001 and November 2001. In Spain, no inter-quarterly falls in GDP occurred during this period.

Global financial crisis. The NBER has recorded the recession between December 2007 and June 2009. In Spain inter-quarterly falls in GDP occurred in the second quarter of 2008 and the whole of 2009.

Source: National Bureau of Economic Research.

impacts of crises on tourism destinations. From the demand side analysis (see Song et al (2012) for a recent revision), many articles concerned with forecasts have usually considered crises to be unpredictable shocks that affect demand and that should be considered to improve the forecasts for a given destination. In these kinds of papers, crises are considered as exogenous elements, an explanation of which is beyond the scope of this research. Other authors (for example, Song et al, 2011) that have concentrated their efforts on modelling tourism demand have focused their attention on demand elasticities and how they are affected by crises (demand segments, supply categories and the deviation effects among destinations, depending on their distance from origin markets and price differentials). Although these considerations are important, the influence of crises on demand omits a large portion of the effect of crises on tourism destinations.

Conversely, from the supply-side perspective, authors have usually studied the response of a part of the industry (hotels, airlines, and so on) to crises (for example, Alonso and Bremser, 2013). The purpose of this research is to learn from these responses, to enable industry managers to make the necessary adjustments to any new shocks that might occur. However, the problem with this research is the difficulty in applying a general conclusion using the results obtained. Therefore, solutions that might be valid for one sector might not be valid for an entire tourism destination, which is a more complex entity with many interactions and with sometimes conflicting interests (Perles et al, 2013).

With respect to articles focusing on economic crises and their impact on tourism destinations, only articles that have analysed the effects of a particular economic crisis on a particular destination or region have been published, and a general study linking all economic crises to tourism competitiveness or market performance could not be found by the authors. 
In chronological order, Schulmeister (1979), Frechtling (1982) and Sanuy (1983), among others, analysed the impact of the energy crises of the 1970s on tourism destinations, showing the resilience of the industry during these crises and highlighting that crises usually go hand in hand with political turmoil, which affects the competitive position of destinations to a greater extent than economic effects.

Twenty years later, the Asian financial crisis at the end of the 1990s was studied by many authors. Prideaux (1999) highlighted the insignificant impact that this crisis had on the tourism sector, which he attributed to the short duration of the crisis. Meanwhile, Henderson (1999) pointed out that destinations with markets of origin mostly in Southeast Asia displayed differentiated behaviour and were more seriously affected by the crisis than destinations with more diversified markets of origin. She also points to the different effects generated by crises in destinations that were in different stages of tourism development. However, in general, these studies emphasized the short-term effects of the crisis on tourism demand, without going into the long-term implications for the competitive positions of the affected destinations (Perles et al, 2013).

In the early 2000s, the Turkish crisis in 2001 also caught the attention of tourism researchers (the 9/11 crisis is not considered here because of its lack of an economic origin). Okumus and Karamustafa (2005) and Okumus et al (2005) analysed the impact of this crisis on the tourism industry in Turkey and Northern Cyprus, highlighting the asymmetrical effects that the same crisis could generate in two different destinations, depending on whether the market of origin was also affected or not. These studies also showed that the response of destinations and types of firms to crises tended to be similar, with reactive and ad hoc measures adopted.

However, the crisis that has attracted the greatest attention from tourism economists is, without a doubt, the last GFC, which has been analysed by Papatheodorou et al (2010), Ritchie et al (2010), Sheldon and Dwyer (2010), Smeral (2010) and Song and Shanshan (2010), among others. These studies once again have revealed the geographic and temporal asymmetries arising from the crisis.

According to Papatheodorou et al (2010), periods of crisis are often characterized by changes in consumer patterns, which translate into new business paradigms aiming to satisfy new and emerging demands. Thus, in addition to the short-term implications for tourism of the current crisis, it is important to highlight some long-term repercussions. The industry is known to be resilient, and it has recovered from many crises in the past. This crisis, however, is particularly challenging because tourist destination leaders must not only address the economic challenges, but they must also respond to the threats of climate change as well as major changes in the nature of travel demand (Sheldon and Dwyer, 2010).

Taking these original ideas into account, this article proposes a theoretical model in which asymmetries play a key role in explaining the long-term implications of economic crises for the success of tourism destinations. As Figure 1 reflects, within the context of a globalizing tourism industry and taking a competitiveness approach, regional crises are more likely to generate asymmetric effects than global crises. Similarly, due to the greater number of 


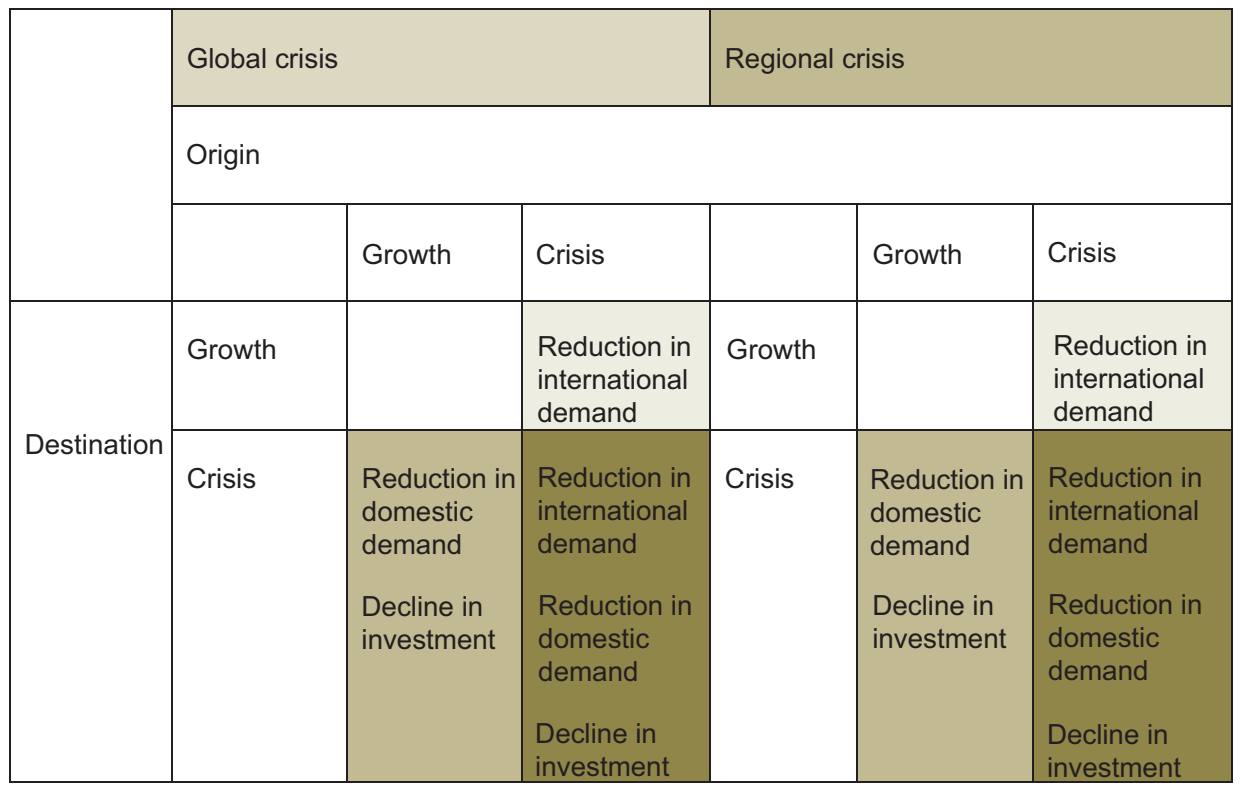

Figure 1. Symmetrical and asymmetrical crises and potential effects on tourism destinations.

Source: Perles et al (2013).

parameters susceptible to being affected, those shocks that have an impact on both markets of origin and destinations are most likely to generate asymmetric effects.

However, before presenting the model and its mechanisms, it is necessary to survey the literature on tourism competitiveness.

\section{Determinants and measurements of tourism competitiveness: a literature review}

Destination competitiveness has become an increasingly important issue because competition from emerging tourist destinations and the changing tastes of tourists are challenging established tourist destinations (Dwyer et al, 2010).

However, defining competitiveness has been a cumbersome endeavour in the literature, with definitions proliferating as more destinations appear in the global marketplace (Croes, 2011). Researchers have agreed that tourism competitiveness is a general concept that encompasses price differentials coupled with exchange rate movements, productivity levels of various components of the tourist industry and qualitative factors that affect the attractiveness or relative desirability of a destination (Dwyer et al, 2000). Applied to tourist destinations, competitiveness seems to be linked to the capacity of a destination to provide goods and services valued by tourists that are superior to those offered by competing destinations (Dwyer and Kim, 2003).

Competitiveness is a relative and multidimensional concept that can be considered from different perspectives, including comparative advantages, strategy and management, and history (Dwyer and Kim, 2003). Attempts to develop indicators of national competitiveness, such as those proposed by Gooroochurn and Sugiyarto (2005), which point to residents' prosperity as the final result 


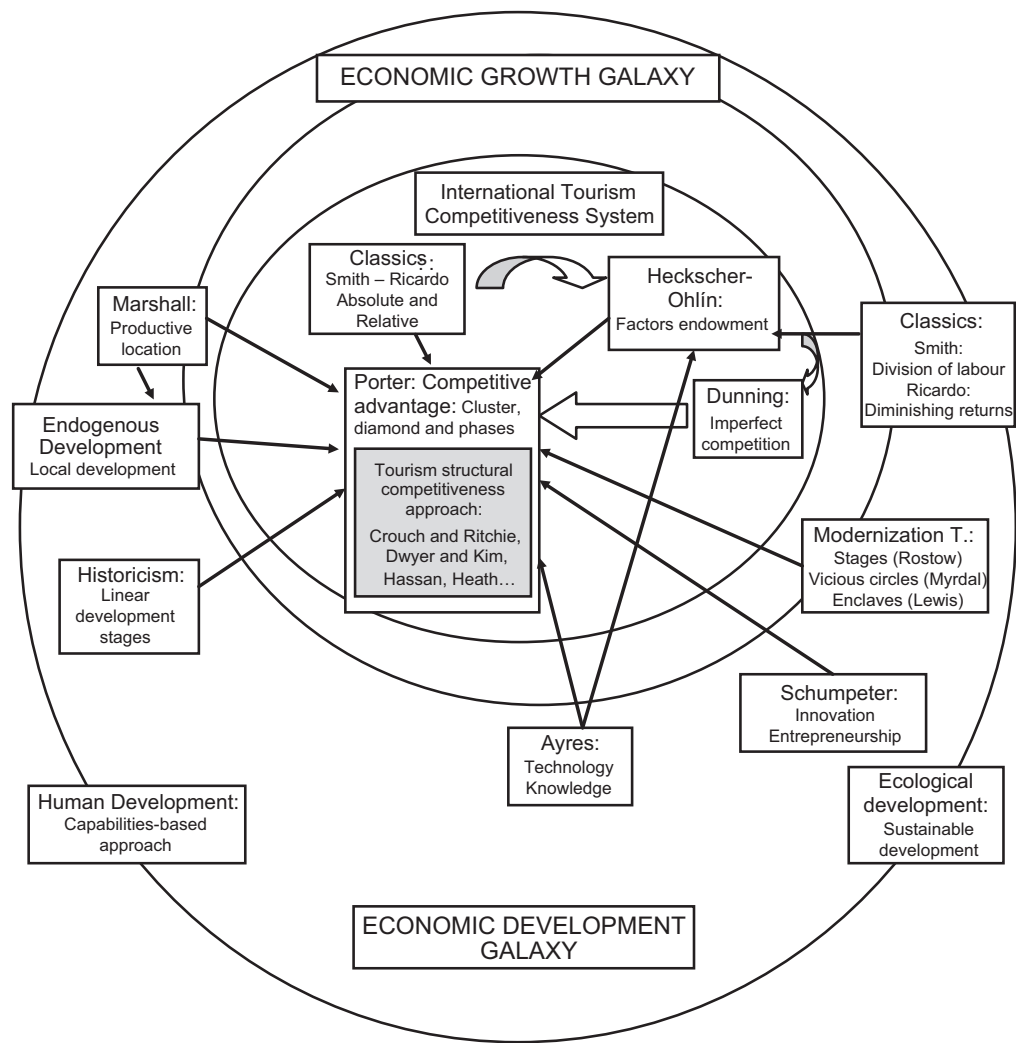

Figure 2. Tourism competitiveness universe.

Source: Author's own elaboration.

of competitiveness, have revealed that the literature on competitiveness cannot be separated from the broader literature on growth and economic development, which considers many elements and interactions (Figure 2).

From a managerial perspective, the conceptual research on tourism destination competitiveness has proposed a comprehensive approach that adds attributes of industry-level competitiveness to more conventional tourism destination attributes (Enright and Newton, 2005). Among the most widely accepted models are those of Crouch and Ritchie (1999), Dwyer and Kim (2003), Hassan (2000) and Heath (2003). In general, these approaches have been based on more or less common and widely accepted definitions, and they have considered different ranges of comparative and competitive advantages. Their differences have resided in the emphasis that they have placed on specific aspects, such as sustainability (Crouch and Ritchie, 1999; Hassan, 2000) or adapting to developing countries (Heath, 2003) or small islands (Craigwell, 2007). Almost all of the models have introduced economic and non-economic elements when explaining competitiveness and have based their theoretical substance on the ideas of Porter (1991).

As explained above, these conceptual models have contemplated economic crises as exogenous factors. Focusing on the most accepted models, according to Crouch and Ritchie (1999), economic crises are parts of the global macro- 
environment of tourist destinations, with the potential to act on this environment through infrastructure and enterprise (supporting factors and resources), a mix of activities (core resources and attractors) and organization (qualifying and amplifying determinants). In Dwyer and Kim's (2003) approach, the effects of economic crises on destination competitiveness arise through situational conditions, which include destination management and demand conditions, corresponding to the qualifying and amplifying determinants in Crouch and Ritchie's (1999) model. Other effects would arise from the created resources and supporting factors and resources in the Resources Box. Finally, in the original diamond competitiveness model (Porter, 1991), the potential effects of crises on competitiveness would arise from demand conditions, the creation of advanced factors and business rivalry among destinations.

Zhang and Jensen (2007), analysing the tourism competitiveness issue from an economic viewpoint, vindicated the importance of comparative advantages. They claimed that there was a basis for applying a more supply-side oriented perspective, along with the more traditional tourism demand studies. In this context, the impact that crises can have on costs and prices are crucial for the competitiveness of destinations. Therefore, in this paper, we select a subset of the competitiveness determinants, representing both comparative and competitive advantages in our attempt to establish a connection between economic crises and the competitiveness of tourism destinations (Table 2).

Finally, with regard to tourism competitiveness measurements, Kozak and Rimmington (1999) stated that destination competitiveness could be evaluated both quantitatively (by looking at data such as tourist arrivals and tourism incomes) and qualitatively (measuring those attributes that holidaymakers liked best or disliked the most during their stays in the destinations, as these factors ultimately drive quantitative performance).

Many studies (see, for example, Kozak and Rimmington, 1999; Enright and Newton, 2004; Perles et al, 2011) have attempted to measure the competitiveness of tourism destinations. However, according to Omerzel and Mihalic (2008), there is no optimal and universal model of competitiveness that can be applied to all destinations, nor is there a generally accepted measurement of competitiveness. In this context, Mazanec et al (2007) pointed out the need to take steps to transform purely defining models and systems into truly explanatory models from an analytical point of view.

In the absence of generally accepted measurements, each author has operationalized the measurement of competitiveness in terms of its subject matter. For example, d'Hauteserre (2000) defined the competitiveness of a tourism destination as its capacity to maintain its position (market share) or to improve its share over time, and maintains that the success of a destination could be determined by evaluating its direct performance in the markets through a market share analysis. However, the use of market share as an indicator of competitiveness has not been exempt from debate. Some authors, such as d'Hauteserre (2000), Craigwell et al (2006) and Mazanec et al (2007), have regarded this variable as a direct measurement of competitiveness and have incorporated it into their studies on its own or together with other elements constituting latent variables. Other authors, however, such as Cracolici et al (2006), Crouch and Ritchie (1999), Dwyer et al (2010) and Enright and Newton (2004), have considered market share to be a measurement of revealed 
Table 2. Economic determinants of competitiveness: different models.

\begin{tabular}{|c|c|c|}
\hline Porter (1991) & Crouch-Ritchie (1999) & Dwyer and Kim (2003) \\
\hline Basic factors & Nucleus of resources and & Provision of resources \\
\hline Natural resources & attraction elements & Natural resources \\
\hline Climate & Physiography & Cultural resources and heritage \\
\hline Landscape, etc & Climate & Created resources \\
\hline Unqualified workforce & Market links & Tourism infrastructure \\
\hline Advanced factors & Mix of activities & Special events \\
\hline Infrastructure & Special events & Range of available activities \\
\hline Qualified workforce & Entertainment & Entertainment \\
\hline Technology & Superstructure & Shopping \\
\hline Conditions of demand & Auxiliary factors and resources & Auxiliary factors and resources \\
\hline Volume of demand & Infrastructure & General Infrastructure \\
\hline Level of understanding and & Accessibility & Quality of service \\
\hline exigency & Accommodation & Accessibility \\
\hline $\begin{array}{l}\text { Related and supporting } \\
\text { sectors }\end{array}$ & $\begin{array}{l}\text { Auxiliary resources: financial } \\
\text { institutions, human capital and }\end{array}$ & $\begin{array}{l}\text { Accommodation } \\
\text { Market links }\end{array}$ \\
\hline $\begin{array}{l}\text { Related companies: tourist } \\
\text { attractions, restaurants, etc }\end{array}$ & $\begin{array}{l}\text { knowledge } \\
\text { c Management }\end{array}$ & $\begin{array}{l}\text { Management of the destination } \\
\text { Organization of the management }\end{array}$ \\
\hline $\begin{array}{l}\text { Auxiliary companies: retail } \\
\text { outlets, services, etc }\end{array}$ & $\begin{array}{l}\text { Management of the destination } \\
\text { Marketing }\end{array}$ & $\begin{array}{l}\text { of the destination } \\
\text { Strategic marketing }\end{array}$ \\
\hline $\begin{array}{l}\text { Structure, strategy and } \\
\text { rivalry of firms }\end{array}$ & $\begin{array}{l}\text { Financing and risk capital } \\
\text { Organization }\end{array}$ & $\begin{array}{l}\text { Tourism policy, planning and } \\
\text { development }\end{array}$ \\
\hline Independent nature & Human resources & Development of human \\
\hline Level of rivalry & IT/research system & resources \\
\hline Commitment to the area & Quality of service & Environmental management \\
\hline Government & Management of visitors/tourists & Localization conditions \\
\hline Investment in providing & Control or protection of resources & Localization \\
\hline factors & Tourism policy, planning & Competitive micro-environmei \\
\hline Tourism promotion & and development & Competitive macro-environment \\
\hline Circumstances & Definition & Health and safety \\
\hline Economic crisis & Perspective & Pricing competitiveness \\
\hline Non-economic crisis & Philosophy & Demand conditions \\
\hline & Positioning & Preferences of tourists \\
\hline & Development & Recognition of the destination \\
\hline & Competitive/collaborative analysis & Image of the destination \\
\hline & Control and evaluation & \\
\hline & Competitive micro-environment & \\
\hline & Macro-environment & \\
\hline & Determinants that increase and & \\
\hline & improve competitiveness & \\
\hline & Localization & \\
\hline & Interdependencies & \\
\hline & Health and safety & \\
\hline & Brand recognition and image & \\
\hline & Price-quality ratio & \\
\hline
\end{tabular}

Source: Authors' own elaboration based on Porter (1991), Croutch and Ritchie (1999), Dwyer and Kim (2003). 
competitiveness or of the final historical results of underlying competitive activity (in prices, differentiation or other elements).

In Perles et al (2013), world market share (in terms of visitor arrivals or revenues) was not considered a true indicator of the competitiveness of a tourism destination but rather an indicator of international tourism success. Obviously the Travel and Tourism Competitiveness Index (World Economic Forum, 2013) would be a better measurement of competitiveness than market share, and other authors have mostly referred to it in the literature regarding tourism revenues, length of stay, GDP per capita, and so on. However, a main disadvantage of this index is the limited period of time for which data are available. Therefore, an empirical study might justify the use of these other indirect measurements of competitiveness as a second-best option (Perles et al, 2014).

However, in a conceptual paper such as this one, we consider that tourism market success and competitiveness indicators should be explicitly separate, believing that a reduction in market share does not necessarily imply a decrease in the levels of development of a tourist destination (Vanhove, 2011). This lack of association occurs because: first, the progressive increase in the market shares of emerging destinations can be seen as a natural phenomenon, as many countries are increasing their levels of development; and second, the growth of destinations is not unlimited, and territories have a maximum reception capacity (Pedreño et al, 1990).

\section{Proposal of a conceptual model and transmission mechanisms of crises on tourism competitiveness}

The main objective of this paper is to propose a conceptual model of the effect of economic crises on tourism competitiveness. Specifically, in our model economic crises affect market performance and residents' well-being through the competitiveness determinants listed in Table 2 (the subset of economic determinants that comprise the basis of the mechanisms are marked in bold and will be explained below). As Figure 3 reflects, the influence of crises on destinations depends primarily upon a crisis's symmetrical or asymmetrical character (that is, whether it is a global or regional crisis), with only regional crises having the potential to cause significant differential effects on destinations during this first stage. A potential factor that influences the possible symmetry or asymmetry of a shock is evidently the size of the origin and/or the tourism destination country. This size may play a very important role in shaping the outcome of a shock in terms of the role of domestic tourism but also in terms of interdependence. For example, a major recession in Germany may result in a reduction of domestic tourism in Germany and inbound tourism of European Mediterranean countries. This is then likely to result in a major crisis in a country like Greece, for example, with subsequently negative effects on its outbound tourism sector.

The model also explicitly recognizes the possibility of the crisis having an endogenous origin generated by the tourism development model of a destination. The market orientation of destinations is also considered in this first stage. It is well-known that different kinds of tourist (for example, leisure, business, 


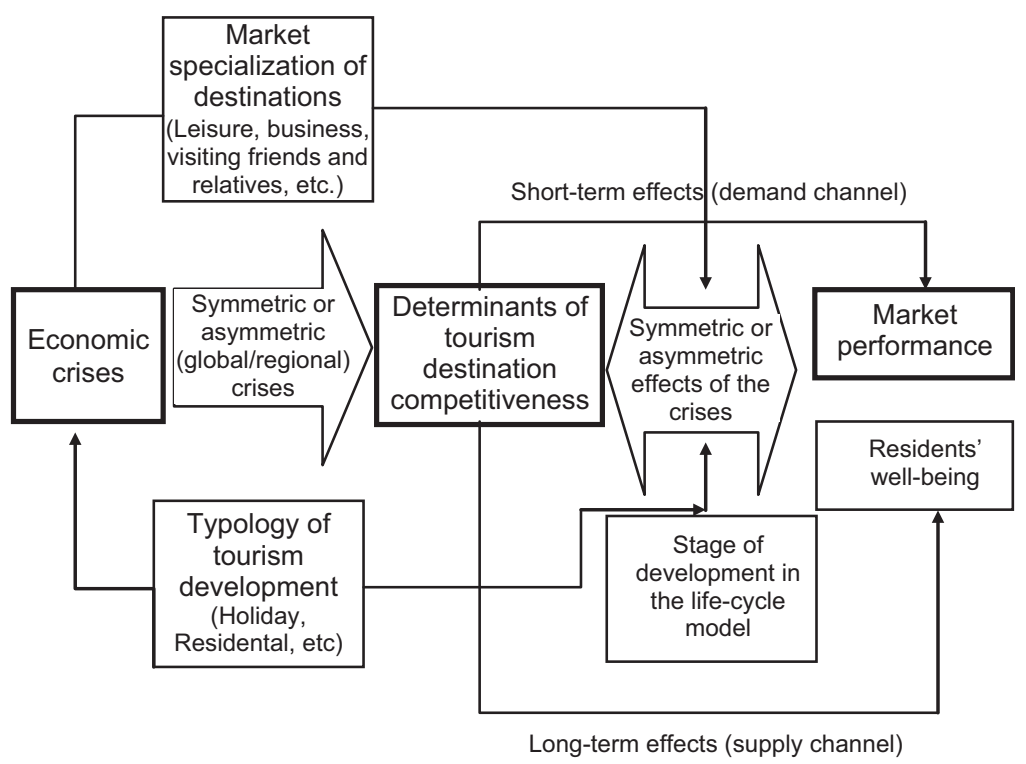

Figure 3. Conceptual model linking economic crises, tourism competitiveness and market performance.

Source: Author's own elaboration.

visiting friends and relatives) often respond differently to crises, so the destination competitiveness response to the crisis is highly influenced by market specialization. In a second stage, the differential effects of both global and regional crises on tourism destinations operate through the competitiveness determinants and are also influenced by the model of tourism development and the stage of the destination in the life-cycle model (Butler, 1980). The model also distinguishes the short-term effects that arise primarily from the effects of the crises on destination demand and the longer-term effects generated mainly by the impact of the crisis on the destination's supply.

From the perspective of determinants of competitiveness, it is important to somehow asses the prevailing market and spatial structure in both the origin and destination areas, as analysed by Papatheodorou (2004). If the tourism flows to a specific destination are largely controlled by a small number of companies and originate from a small number of origin areas, then the impact of any crisis on a destination may be larger as a result of greater risk exposure to business insolvencies or adverse cyclical fluctuations in an origin economy. In contrast, a destination can reduce risk by following a portfolio approach to attract tourists from different service providers and origin areas.

Figure 4 summarizes the causes and mechanisms that relate economic cycles to the competitiveness of tourism destinations, which, consistent with Figure 3 , distinguishes between transmission mechanisms operating on the demand side and those operating on the supply-side. The former mechanisms affect the destination's competitiveness immediately and translate into a rapid reduction in the destination's market share if the deviation of tourists between competing destinations occurs during the crisis. The reduction in demand can also indirectly affect competitiveness through the potential impact on the profitability 


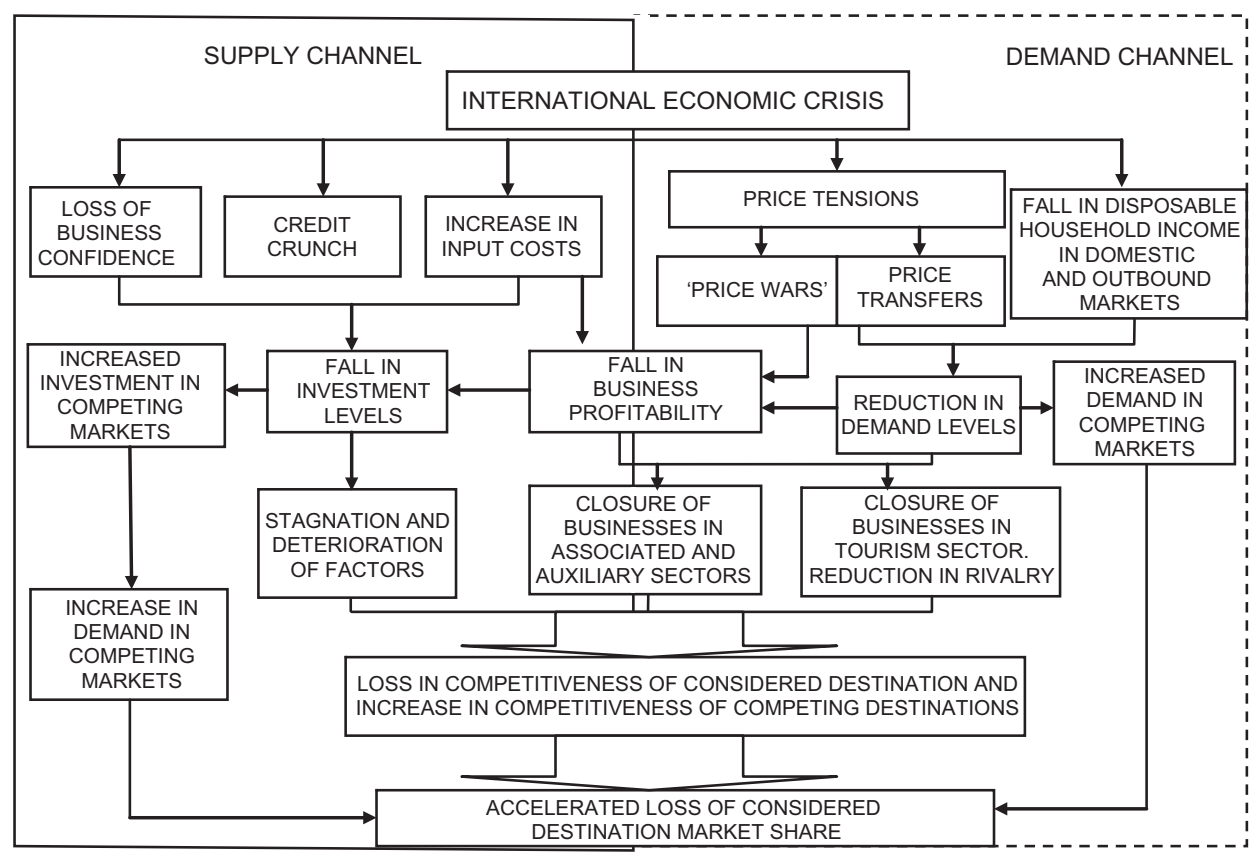

Figure 4. Theorized transmission mechanisms between economic crises and tourism competitiveness.

Source: Adapted from Perles et al (2013).

of tourism companies, associated and auxiliary sectors, the levels of rivalry and negative effects on the government, which will collect fewer taxes associated with tourism consumption and profits, thereby lowering its capacity to invest in generic and specific advanced factors for the sector. Transmission mechanisms operating on the supply-side have delayed effects on competitiveness over the medium and long term, reinforcing natural trends of losses or gains in competitiveness, depending on whether the destination is an emerging or a mature market, by reducing the capacity to create advanced factors in crisis-affected destinations. Consequently, these destinations will have a worse competitive position over the medium and long term, in comparison to other destinations unaffected by the crisis.

The demand- and supply-sides are not independent; there is important interaction between them, with expectations being the primary element connecting the two mechanisms. These expectations can either aggravate or moderate the above-mentioned effects, and they will be examined in greater detail below.

\section{Demand mechanisms}

Establishing the determinants and predicting the volume of demand have been among the primary focuses of research in tourism economics for some time. In addition to the many studies that have been performed, there have also been several reviews and compilations regarding the determinants, functional forms and data used when analysing tourism demand. Our perspective of how demand 
mechanisms operate is based on the reviews of Crouch (1995), Li et al (2005), Lim (1997), Witt and Witt (1995) and Song and Li (2008).

\section{Reduction in disposable income}

According to Lim (1997), tourism demand modelling has usually been based on a function in which the dependent variable is the demand for international tourism services between an origin and a destination, and the explanatory variables are the level of income in the country of origin, the transport costs between the origin and the destination, the relative prices in the country of origin, the destination and competing destinations, the exchange rates of the currencies and a broad range of qualitative factors that affect the destination. With regard to income (usually measured in real GDP or real GDP per capita), it is expected, in theory, that as income increases, the demand for luxury goods and services also increases. Furthermore, it can be expected that tourism demand is not only influenced by current income but also by its historical evolution, given that changes in income can take some time to affect tourism demand (Lim, 1997).

Some studies, for example Song et al (2003), have identified income as a principal determinant of tourism demand. Not surprisingly, the omission of this highly relevant variable of demand can be disastrous for research (see Witt and Witt (1995) for their criticism of this matter). The majority of studies have analysed demand in terms of elasticities. Income elasticity of demand varies both with the different origins and destinations considered (Divisekera, 2003) and with the products and segments analysed. Moreover, elasticity is influenced by the prevailing economic climate (White, 1985; Durbarry and Sinclair, 2003). However, in general terms, tourism demand is usually tremendously elastic, whereby disposable household income immediately affects demand in this sector; see Crouch (1995), Smeral and Witt (1996), Smeral and Weber (2002) and $\mathrm{Li}$ et al (2005) for income elasticities of greater than one in several cases. Under these circumstances, it can be assumed that economic crises have negative effects on the competitiveness of destinations. However, the set of interactions that occur are more complex than we might expect, and the final effects of crises on market shares depends on whether these crises are symmetrical or asymmetrical.

In general, economic shocks reduce disposable household income. When a crisis is asymmetric and it does not have an impact (or its effects are not sustained over time) in all areas of the world in the same way, for the same length of time or with the same intensity, there will be differentiated effects on tourism competitiveness. These effects, aggravated by the income elasticity mentioned above, are manifested in rapid changes in the shares that the different destinations have of the global market. With regard to crises such as the current situation, with a much more intense impact on the USA and Europe than on East Asia or on parts of South America, from a theoretical point of view, it is predicted that the market share of destinations in the US and Europe will fall rapidly, and those in the latter regions will increase.

If we take Spain as an example of a mature destination, in the short term and only in terms of demand, three reactions might be expected from European tourists who have experienced a reduction in their disposable income. First, they might forego their vacations, remaining in their place of origin, which is highly 
probable, given that the profile of Spain's tourism demand is one with a medium-low income and particularly if the reduction in income is also combined with unemployment. Second, they might prefer to substitute their previous trips to long-distance destinations, choosing Spain as their destination over other competitors, which is less likely because the high-income segments of demand are precisely those that are less affected by the crisis. Third, they might prefer to substitute their previous trips to long-distance destinations and those in the Spanish market with holidays in less expensive and closer destinations (Turkey, or Morocco), which is highly probable. The final result is inconclusive and will depend on the predominant effect, although it seems logical to believe that Spain will experience a reduction in the level of its tourism demand. Apart from these immediate effects on market share, there are other pernicious effects for the competitiveness of destinations over the medium and long terms, caused by the decrease in demand due to the relationships between the different determinants of the diamond model of competitive advantage.

\section{Evolution of prices and exchange rates}

According to Lim (1997), relative prices are the second most common explanatory variable in modelling the functions of tourism demand, and some writers (for example, Dwyer, 2001) have considered prices to be the key variable in competitiveness. As a proxy for relative prices, many empirical studies have used consumer price index (CPI) ratios between origins and destinations, adjusted for the exchange rate between them. However, there have been cases in which the two variables have been introduced separately in the estimate (Lim, 1997).

In theory, it would be expected that a decline in the price competitiveness of a destination would translate into a significant reduction in its demand (Dwyer et al, 2010). Therefore, a crisis that causes an overall increase in prices in the destination will ultimately affect its demand and, depending on the price evolution experienced by its competitors, its global market share.

Crouch (1995), Witt and Witt (1995), Durbarry and Sinclair (2003) and Patsouratis et al (2005), among others, highlighted the negative price elasticity of demand. Buisán (1997) and González and Moral (1996) found that price competitiveness, regarding both outbound markets and competitors, was the most relevant variable explaining international inbound demand to Spain. They also identified two stages in the price evolution of Spanish tourism: a first stage lasted until the mid-1980s, when the behaviour of prices contributed positively to tourism demand; and a second stage began after Spain joined the European Common Market, when tourism demand was affected negatively by the behaviour of prices and the appreciation of the peseta.

During periods of crisis, tourists are highly price sensitive. Therefore, neither increasing prices nor forcing their control (action taken through price wars with no improvements in the efficiency of tourism companies) will favour competitiveness. During an asymmetrical shock, such as the present situation, three differentiated scenarios can be defined. First, with regard to destinations within crisis-stricken areas, if there is an overall price increase in all of the destinations - stagflation - the increased sensitivity of clients to price will induce them to choose less expensive alternatives. This effect will lead to a reduction in the market shares of the more expensive crisis-affected destinations and increase the 
shares of less expensive destinations, whether they are affected by the crisis or not. These results will be more or less pronounced, depending on which destinations increase their market shares (whether they are among the most expensive or least expensive destinations) and which lose their market shares, as the degree of asymmetry of the crisis is such that the prices in some of the affected destinations increase, whereas in others, they decrease. Finally, if prices stagnate, if deflation occurs in the area affected by the crisis and if in the unaffected area, prices continue to experience normal growth rates, then the impact on market shares will once again depend on the final price differentials between destinations in the two areas. The region affected by the crisis might attract tourists from the unaffected area, drawing them with the low prices.

Similar to income, apart from these short-term effects on demand flows caused by price variations, there are other medium- and long-term effects on competitiveness. These effects are not justified by improvements in efficiency in the tourism companies which sacrifice business profitability, due to price wars that arise from crises. These changes have harmful effects on the creation of factors, as in the case of income. The impact of price variations on competitiveness can be managed through economic policy measures, at least temporarily, via alterations in the exchange rates of the different currencies. However, such management is impossible when a destination forms part of a fixed exchange rate commitment or a single currency, as in the case of Spain since 1999.

\section{Expectations and other elements}

Expectations can aggravate or mitigate the effects mentioned above, and they constitute the connection between demand and supply mechanisms. On the demand side, expectations during recessions are associated with unemployment and the adverse psychological effects caused by continual negative news reported by the media, leading to a contraction of tourism demand in those countries affected by a crisis. Therefore, negative expectations in both countries of outbound tourism and in destination countries, paralyzing domestic tourism, are harmful to the competitiveness of the destination, and depending on their intensity, can generate reductions in these locations' global market shares.

There are other elements, such as travel costs, tourism marketing budgets and internal demand that could aggravate or mitigate the above-mentioned effects. All of these elements, which are modified during periods of recession, can act as transmission mechanisms of competitiveness. However, they do not fall within the scope of this study, although they are no less relevant for tourism competitiveness.

\section{Supply mechanisms}

Supply mechanisms describe the effects that shocks can have on investment, and they can be derived in three different ways: an increase in input costs associated with many economic crises; credit crunches in the case of financial shocks; and a reduction in usual business confidence during periods of recession. The joint action of these elements alters business and government investment in the domestic economy and foreign direct investment (FDI) from abroad, thereby modifying the relative working capital composition of tourism products in the 
different destinations. This change in composition affects these locations' competitiveness over the medium and long term. These mechanisms have become more prominent since the 1990s, with increased globalization and the gradual deregulation of goods, services and capital markets, including tourism.

The causes and determinants of investment as a whole and of FDI in more specific terms have been widely discussed in the economic literature. This study has considered the contributions of Dwyer and Forsyth (1994), Dwyer et al (2010), Endo (2006), Fontagné and Pajot (1997) and Hill and Jongwanich (2009) among others. Domestic investment, both corporate and governmental, increases during growth periods of the cycle and decreases during periods of crisis. Therefore, the effects of this mechanism are generated not because investment is higher in absolute terms during periods of crisis than during economic growth periods but because in comparative terms, those destinations unaffected by crises can invest relatively more, experiencing less variability in investment than crisis-affected destinations.

During an asymmetric shock, international investment flows, both in the form of FDI and portfolio investment, seek opportunities in destinations unaffected by the crisis. Some investment is even made in unaffected areas of the crisis-stricken destinations (Levy-Yeyati et al, 2003). In this respect, the investment flows generated during periods of crisis are less relevant than the influence that shocks have on investment decisions, as in the case of the internationalization of the Spanish hotel industry during the Spanish tourism crisis from the mid to late 1980s (Ramón, 2002). There might be a delay in the materialization of opportunities detected during periods of crisis, which take shape in the subsequent growth phase; although the important point is that the decision will have been made during the recession. One final element to be considered resides, as in the case of demand, in the regional nature of many crises. In such cases, apart from the potential flow of investment between affected destinations toward those that have not been affected by the crisis, there are also investment flows between blocks of unaffected countries. This situation is currently visible, for example, among emerging countries and is sufficient to alter the distribution of market shares of the different destinations over the medium term, depending on how they have been affected by the crisis.

Despite the complexity of the mechanisms described, the final effect on competitiveness is less ambiguous than that observed in the case of demand, given that the majority of effects indicate a greater loss of the competitiveness in destinations affected by crises than those that are not. The following section analyses how supply mechanisms work, with an emphasis on their influence on FDI.

\section{Increase in input costs}

Experience has shown that many economic shocks go hand in hand with cost increases (energy and raw materials), which affect profitability and reduce profit margins and the capacity to invest in the creation of competitive factors. Such was the case of the energy crises of the 1970s, the crisis at the beginning of the 1990s and the initial phases of the current global financial crisis. When increases in operating costs cannot be transferred to clients without reducing demand, there is a fall in corporate profitability, which threatens the viability of tourism and its associated and auxiliary companies. These effects induce 
companies in the affected destinations to diversify risks in other markets, possibly fostering a flow of investment from crisis-affected destinations toward unaffected destinations. If this fall in profitability caused by increased costs is combined with stagnation of demand generated by the recession, it is likely that international financial investors will cease to invest in affected destinations, favouring those destinations experiencing growth.

In the short and medium term, as investment flows foster the movement of tourists from one destination to another (an effect described by Dwyer and Forsyth (1994)), the market share of the destinations will change, with those of unaffected destinations increasing to the detriment of those of the crisisstricken destinations. Over the long term, the lower relative levels of investment in creating factors in the crisis-affected areas, compared to those of destinations unaffected by the crisis, will enhance the competitiveness of the latter and reduce that of the former. Therefore, the effects that were initially considered to be temporary will persist over time.

\section{Credit squeezes for corporations, housebolds and governments}

A second element derived from crises that could potentially affect the competitiveness of tourism destinations are credit crunches. Economic or financial shocks usually derive increased capital costs and financial restrictions for corporations, households and governments. These changes alter investment patterns, which can modify the medium-term competitiveness of tourism destinations. Investment in tourism is particularly sensitive to the prevailing situation of the tourism sector and that of the economy as a whole. A stable economic environment stimulates investment, particularly in projects with long or very longterm returns related to increases in the production capacity of the company. In contrast, uncertainty and economic downturns tend to reduce this type of investment and replace it with simple renewal of the most obsolete assets.

An increase in interest rates raises financial costs for corporations and governments, negatively affecting tourism and non-tourism investment projects and is detrimental to other more attractive financial alternatives. With regard to the corporate sector, if companies cannot reinvest their declining profits in creating factors, they will have no incentive to seek external financing to do so, as the little money available will be lent at interest rates that will render the projects unfeasible. In short, less available and more costly credit reduces investment by all economic agents in advanced factors, with a negative impact on the competitiveness of crisis-affected destinations over the medium and long term. When this availability is asymmetric, the effects on competitiveness will vary between destinations and will be reflected in their shares of the world tourism market.

\section{Loss of business confidence}

Loss of business confidence is the equivalent on the supply-side of expectations on the demand side. When a loss in confidence is coupled with negative demand expectations, the effects of a crisis on competitiveness are multiplied. When there is no business confidence, there is no investment, and it is difficult for private companies to create advanced factors. The concurrence of the negative effects of expectations on competitiveness is highly visible in the present financial crisis, in which both business and consumer confidence levels are very 
low. As in the case of demand, the authors of this study acknowledge the existence of other elements that could influence competitiveness. The most relevant is the response of government authorities to the crisis, which will depend on the state of public finance and the economic policies implemented. Tourism investment programs could play a predominant role in this response. However, due to limited space, this study will not address these effects in detail.

\section{FDI and tourism competitiveness}

A primary effect of these supply mechanisms on the competitiveness of destinations operates through FDI. According to Endo (2006), the apparent demand of FDI for tourism is high. Today, capturing investment for tourism is one of the main activities of investment promotion agencies in developing countries. With regard to supply, the majority of FDI comes from more developed countries. The results reveal positive relationships between FDI and competitiveness in the industrial case (Fontagné and Pajot, 1997), and although Dwyer and Forsyth (1994) expressed reservations in the case of tourism (leakages), there is no reason to believe that the situation in the tourism sector is any different.

Logic tells us that in the race to capture international funds for investment unaffected destinations are those that benefit during periods of crisis. However, empirical evidence has revealed that even crisis-affected countries or destinations can receive an inflow of international capital in the form of FDI. This capital, together with the regional nature of investment in tourism, clearly favours emerging destinations, as opposed to the more mature markets, in their efforts to increase their competitiveness (Stern, 1993). Hill and Jongwanich (2009) pointed out that, paradoxically, FDI inflows can increase during periods of crisis, although with a flight of capital in the short term. This effect can be explained by the different causes of the two types of investment. In the case of Thailand, these authors observed that during the Asian crisis, inflows and outflows of FDI behaved differently. Inflows grew strongly, and outflows decreased sharply, leading to an improvement in Thailand's competitiveness over the medium and long term.

With regard to the current crisis, the United Nations Conference on Trade and Development (UNCTAD, 2009) indicated that 2008 marked the end of a growth period in world FDI between 2003 and 2007 and confirmed the asymmetry of the crisis as it has had a greater impact on developed countries (which have suffered sharp declines in FDI) than on developing countries. It also revealed that in the current crisis, the impact experienced by different countries has depended on their different degrees of international openness. Finally, it emphasized the relevance of the supply channels described, indicating that reductions in access to credit, negative forecasts and risk aversion have been the main causes of the decline in global FDI flows, highlighting the strength of emerging economies as new sources of FDI.

\section{Empirical analysis: the effects of economic crisis on Spanish tourism competitiveness}

An empirical analysis of the afore-mentioned mechanism was carried out for Spain using the time frame of 1970-2013. Unlike the previous studies of Perles 
et al (2013) and Perles and Ramón (2013b), and in order to achieve greater flexibility in the estimated models, in this paper a non-linear approximation is used. Specifically, several threshold regressions of Spain's market share (measured in terms of visitor arrivals) with respect to representative variables of the economic cycle and crises and the mechanism are performed.

\section{Switching Regression Methodology}

Threshold regressions and Markov switching regressions (both belonging to a broader family of switching regression models) have been applied by several authors to different tourism issues (Fernando, 2010; Kun-Huang et al, 2011). They have been used for applications in demand forecasting by Beaman et al (2001) or Taplin (2003); by Uysal et al (1995) for modelling destination or trip type choice; by Moore and Whitehall (2005) to explain destinations lifecycle; by Chia-Lin et al (2012) for establishing links among tourism specialization and economic development and by Ming-Hsiang (2014) for analysing the effects of monetary policy in the tourism industry stock performance. However, this article is the first to apply these kinds of specifications to the field of destination competitiveness.

Following Teräsvita et al (2010), the standard switching regression (SR) model is piecewise linear, can be generally defined as follows:

$$
y_{t}=\sum_{j=1}^{r+1}\left(\mu_{j}+\varnothing_{j} z_{t}+\varepsilon_{j t}\right) I\left(c_{j-1}<s_{t} \leq c_{j}\right)
$$

where $z_{t}=\left(w_{t}^{\prime}, x_{t}^{\prime}\right)^{\prime}$ is a vector of explanatory variables, with $w_{t}=\left(y_{t-1}, \ldots, y_{t-p}\right)^{\prime}$ including $p$ lags of the dependent variable, and $x_{t}=\left(x_{1 t}, \ldots, x_{k t}\right)^{\prime}$ denoting a $k$ vector of (weakly) exogenous variables. The $s_{t}$ process is an observable variable, usually assumed to be a continuous stationary random variable, for which the set of threshold values $c_{0}, c_{1}, \ldots, c_{r+1},\left(c_{0}=-\infty, c_{r+1}=\infty\right)$ defines $r$ latent states that characterize non-linear responses in the dependent variable as captured by the parameters $\mu_{j}$ and $\varnothing_{j}, j=1, \ldots, r+1$. Finally, $\left\{\varepsilon_{j t}\right\}$ denote a sequence of random perturbations having zero mean and constant variances $\sigma_{j}^{2}$ that may vary across these regimes. Note that if $r=0$, there exists only a single regime and the model renders the well-known linear model that can be estimated by ordinary least squares.

The main aim is to characterize the vector of unknown parameters $\theta=\left(\mu_{1}, \ldots\right.$, $\left.\mu_{r+1}, \varnothing_{1}^{\prime}, \ldots, \varnothing_{r+1}^{\prime} \sigma_{1}, \ldots, \sigma_{r+1}\right)^{\prime}$ as well as the vector of threshold parameters $c_{1}, \ldots, c_{r}$ that define the latent regimes. The estimation of these parameters can be carried out by conditional least squares. For ease of exposition, but no loss of generality, assume $r=1$ such that a single threshold parameter $c_{1}$ defines two regimes. This procedure determines the conditional estimate of the $\theta$ vector as the minimizer of the sum of squared residuals (SSR) of Equation (1) given an arbitrary value of $c_{1}$ in a certain close interval $\Omega_{C}$. The consistent estimate of $\left(\theta^{\prime}, c_{1}\right)^{\prime}$ can be determined as the values that minimize the SSR for any value in $\Omega_{C}$ using a sequential procedure. Chan (1993) provides an asymptotic distribution for the threshold parameter estimates, which unfortunately depends on nuisance parameters. Hansen (2000) derives the asymptotic distribution of the estimator in the context $z_{t}=x_{t}$ and $s_{t}$ exogenous, showing that the estimates of the threshold parameters are free of nuisance parameters. This opens up the possibility of 
testing hypothesis about these coefficients and likelihood-ratio test for addressing the general suitability of the non-linear threshold model against a restricted, simpler linear specification.

In this paper, we use Hansen's approach to estimate several threshold models. In all these models, we consider the variation of Spain's market share as dependent variable, and (lagged) values of the variation of the Spanish GDP as threshold variable. Consequently, the central hypothesis is that different economic scenarios, as captured by GDP growth, may define heterogeneous characteristic responses in Spain's market share which may show sheer differences across regimes. Consistent with previous literature, we consider a tworegime model $(r=1)$ aiming to capture difference between expansive and contractive cycles in the economy. The two-regime approach is parsimonious representation suffices to capture the most salient nonlinearities in practice (Teräsvita et al, 2010:33). The interval $\Omega_{C}$ is given by the support of this variable after trimming out the top 5 percentiles. The different specifications estimated in the empirical implementation differ only in the set of explanatory variables considered in the right-hand side of Equation (1). The most general case considers as explanatory variables lagged values of GDP, the variation of international price competitiveness adjusted by exchange rates (RCPI), the variation gross capital formation $(\mathrm{GKF})$ and the variation of cement consumption (representing generic national investment), the variation of inward and outward FDI and the variation of Spanish unemployment rate (representing expectations) are used as explanatory variables. Note that all variables are determined as logarithmic differences and lagged one period. The estimations are performed using the programming language R 3.1.0 (R-Core Team, 2014) and the code provided by Hansen in his personal web page (see references).

The equations representing the models performed, where the sub index ' $i$ ' is an indicator of the corresponding regime, are as follows:

$$
\begin{aligned}
& d \ln (M S H A R E)=\alpha_{r i}+\beta_{1 r i} d \ln (G D P)+\beta_{2 r i} d \ln (R C P I)+\beta_{3 r i} d \ln (U N E M P L O Y) \\
& +\beta_{4 r i} d \ln (F D I i n)+\beta_{5 r i} d \ln (F D I o u t)+\beta_{6 r i} d \ln (G K F)+\mu_{r i}(\text { Models } 1 \text { and } 4) \text {, } \\
& d \ln (M S H A R E)=\alpha_{r i}+\beta_{1 r i} d \ln (G D P)+\beta_{2 r i} d \ln (R C P I)+\beta_{3 r i} d \ln (U N E M P L O Y) \\
& +\beta_{4 r i} d \ln (F D I i n)+\beta_{5 r i} d \ln (\text { FDIout })+\beta_{6 r i} d \ln (B E D S)+\mu_{r i}(\text { Models } 2 \text { and 5), } \\
& d \ln (M S H A R E)=\alpha_{r i}+\beta_{1 r i} d \ln (G D P)+\beta_{2 r i} d \ln (R C P I)+\beta_{3 r i} d \ln (U N E M P L O Y) \\
& +\beta_{4 r i} d \ln (F D I i n)+\beta_{5 r i} d \ln (F D I o u t)+\beta_{6 r i} d \ln (C E M E N T)+\mu_{r i}(\text { Models } 3 \text { and 6). }
\end{aligned}
$$

The models only differ in the variable used to represent the general or tourism investment. In models 1 and $3 \mathrm{GKF}$ is used, in models 2 and 4 hotel tourism beds (BEDS) are used and finally in models 3 and 5 cement consumption (CEMENT) is used.

\section{Data and results}

Table 3 lists the variables considered, the source used and the observations pertaining to each case. Unlike the previous studies conducted by Perles et al (2013) and Perles and Ramón (2013b), here the variables are transformed into their logarithmic difference - whereas the former studies used the log-levels 


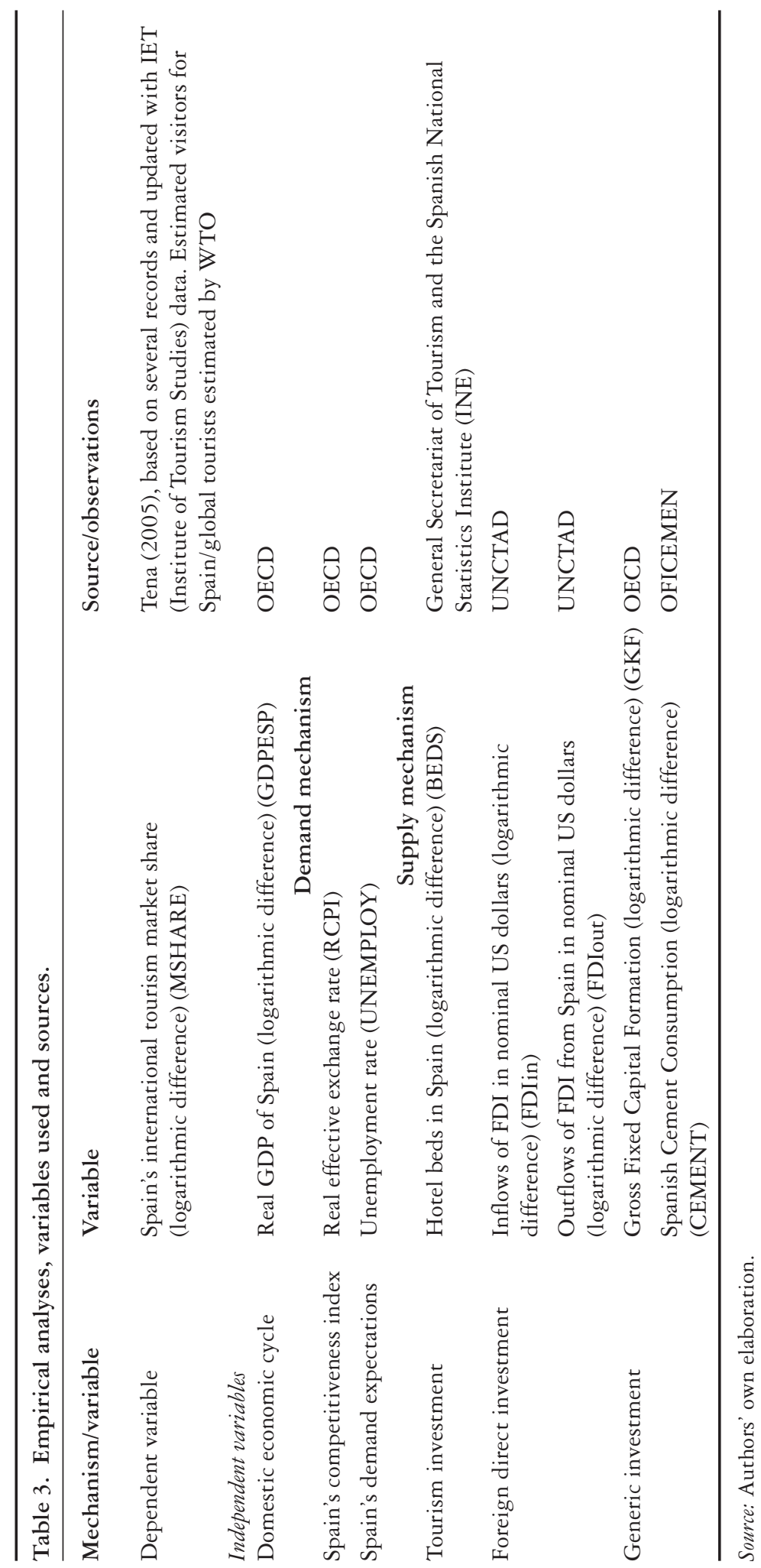


Table 4. Descriptive statistics, 1970-2013.

\begin{tabular}{lrrrrrrr}
\hline Variable & N & Mean & $\begin{array}{c}\text { Standard } \\
\text { deviation }\end{array}$ & Min & Max & Skewness & Kurtosis \\
MSHARE & 43 & -0.01 & 0.06 & -0.18 & 0.16 & -0.16 & 0.50 \\
GDPESP & 43 & 0.03 & 0.02 & -0.04 & 0.08 & -0.27 & 0.21 \\
RCPI & 43 & 0.01 & 0.05 & -0.13 & 0.14 & -0.52 & 2.55 \\
UNEMPLOY & 41 & 0.06 & 0.16 & -0.28 & 0.47 & 0.50 & 0.08 \\
BEDS & 43 & 0.03 & 0.05 & -0.05 & 0.28 & 3.38 & 15.34 \\
FDIin & 43 & 0.12 & 0.49 & -2.00 & 1.34 & -1.51 & 6.71 \\
FDIout & 43 & 0.15 & 2.33 & -10.63 & 10.17 & -0.46 & 15.48 \\
GKF & 43 & 0.02 & 0.07 & -0.20 & 0.13 & -0.53 & 0.27 \\
CEMENT & 43 & -0.01 & 0.13 & -0.41 & 0.15 & -1.34 & 1.43 \\
\hline
\end{tabular}

Source: Authors' own elaboration.

of the variables. For this reason, our results should be interpreted in terms of variation rates. Linear or quadratic trends are not included in our estimations.

Figure 5 shows the evolution of the variables considered in the analysis and Table 4 summarizes the descriptive statistics of each variable. The table shows that the evolution of tourism competitiveness in Spain measured by its share in the global market is characterized by an underlying declining trend (mean of annual decrease of 1\%) which is explained by the natural emergence of new competing destinations within a context of an accelerated globalization of the tourism sector and by the maturity of its main tourism product (sun and beach), in accordance with the destination lifecycle model (Butler, 1980).

This decrease in the Spanish market share was combined with moderate economic growth for the whole period but with a significant increase in unemployment, which is one of the distinguishing characteristics of the Spanish economic system. With regard to Spanish price competitiveness, the country's economy has been losing its external competitiveness, as shown by the positive value of the real effective exchange index. Finally, the increase in generic investment and FDI is proof of the opening and modernization of the Spanish economy during this period.

The standard deviation and the range (min-max columns) show that FDI both, inward and outward - has been the most volatile variable. Meanwhile, we can observe that the tourism market share was highly volatile until 1990 and more stable from this year until 2013.

A correlation analysis shows that the market share is negatively correlated with price competitiveness and unemployment and there is a positive association with GDP growth and cement consumption. However, none of these correlations is significant, which justifies the use of a non-linear approach in the analysis. Strong significant contemporaneous correlations exist between GDP growth and unemployment $(-0.596)$ and between GDP and variables representing generic investment $(0.913$ between GDP and GKF and 0.881 between GDP and cement consumption). Medium but significant correlations exist between generic and FDI investment (FDIin-GKF 0.417; FDI-Cement $0.354)$. This degree of association decreases when different lags are considered for the considered variables. Finally, no correlation is observed between BEDS (the variable representing tourism investment) and any other variable. One 

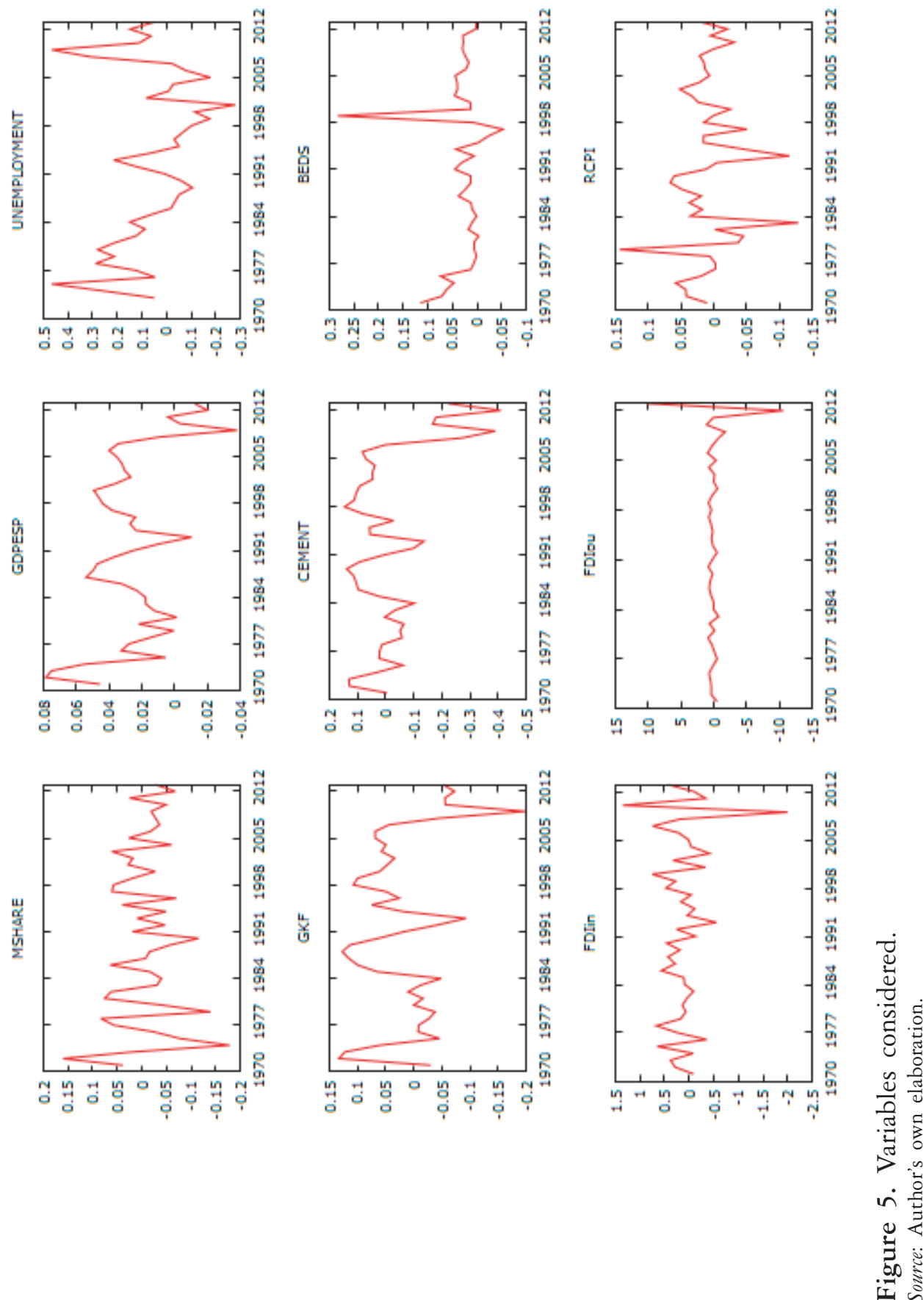
Table 5. Global OLS models without threshold variable.

$\begin{array}{ccc}\text { Model 1 } & \text { Model 2 } & \text { Model 3 } \\ \text { Estimates (Std error) } & \text { Estimates (Std error) } & \text { Estimates (Std error) }\end{array}$

CONSTANT

$\operatorname{GDPESP}(-1)$

RCPI

$\operatorname{UNEMPLOY}(-1)$

BEDS(-1)

$\operatorname{FDIin}(-3)$

FDIou(-3)

$\operatorname{GKF}(-2)$

CEMENT(-2)
0.008528

(0.01846)

$-0.322450$

(0.69869)

$-0.455838$

$(0.17096)^{* * *}$

$-0.130334$

$(0.06080)^{* * *}$

$-0.254490$

$(0.14125)^{*}$

0.057143

$(0.01759)^{* * *}$

$-0.022953$

$(0.01887)$
$-0.01038$

$(0.02438)$

0.13450

(0.97043)

$-0.40299$

$(0.16830)^{* *}$

$-0.12670$

$(0.06647)^{*}$

0.05483

$(0.01746)^{* * *}$

$-0.01332$

(0.01936)

$\mathrm{N} / \mathrm{DF} / \mathrm{R}^{2}$

$40 / 33 / 0.38$

$40 / 33 / 0.31$

$40 / 33 / 0.30$

Source: Authors' own elaboration. Std errors: Standard White Heteroskedasticity Consistent Errors HC0. Significance codes: ${ }^{*} 0.1 ;{ }^{* *} 0.05 ;{ }^{* * *} 0.01$.

possible explanation lies in the importance of residential tourism in this country, which casts doubt on the quality of this variable as a proxy for tourism investment in the Spanish case.

Table 5 shows the results of the global models 1, 2 and 3 estimated by ordinary least squares models without a threshold variable. In order to be consistent with the dynamics of the afore-mentioned mechanism, the variables representing the generic investment of the supply channel are introduced with two (GKF or CEMENT) or three lags (both types of FDI). Meanwhile, the variables representing the demand channel and the business cycle are included with only one lag. The introduction of these lags also prevents problems of endogeneity. Only price competitiveness (RCPI) is included in our regressions without lags, because the effect of this variable on competitiveness can be considered as almost immediate. Due to the small sample size it is very difficult to obtain statistically significant levels for the variables, but the estimated models show how price competitiveness (RCPI), expectations linked to the economic cycle (UNEMPLOYMENT) and FDI are significant in all global models. The generic investment variable is significant when gross capital formation is considered (model 1), and tourism investment (BEDS) is significant in its corresponding model (model 2).

Table 6 shows the result of the switching models when the logarithmic difference of GDP is used as a threshold variable (models 4, 5 and 6). The first row of the table shows that the estimated threshold for determining whether a country is experiencing an economic crisis in the sense of this research ranges 


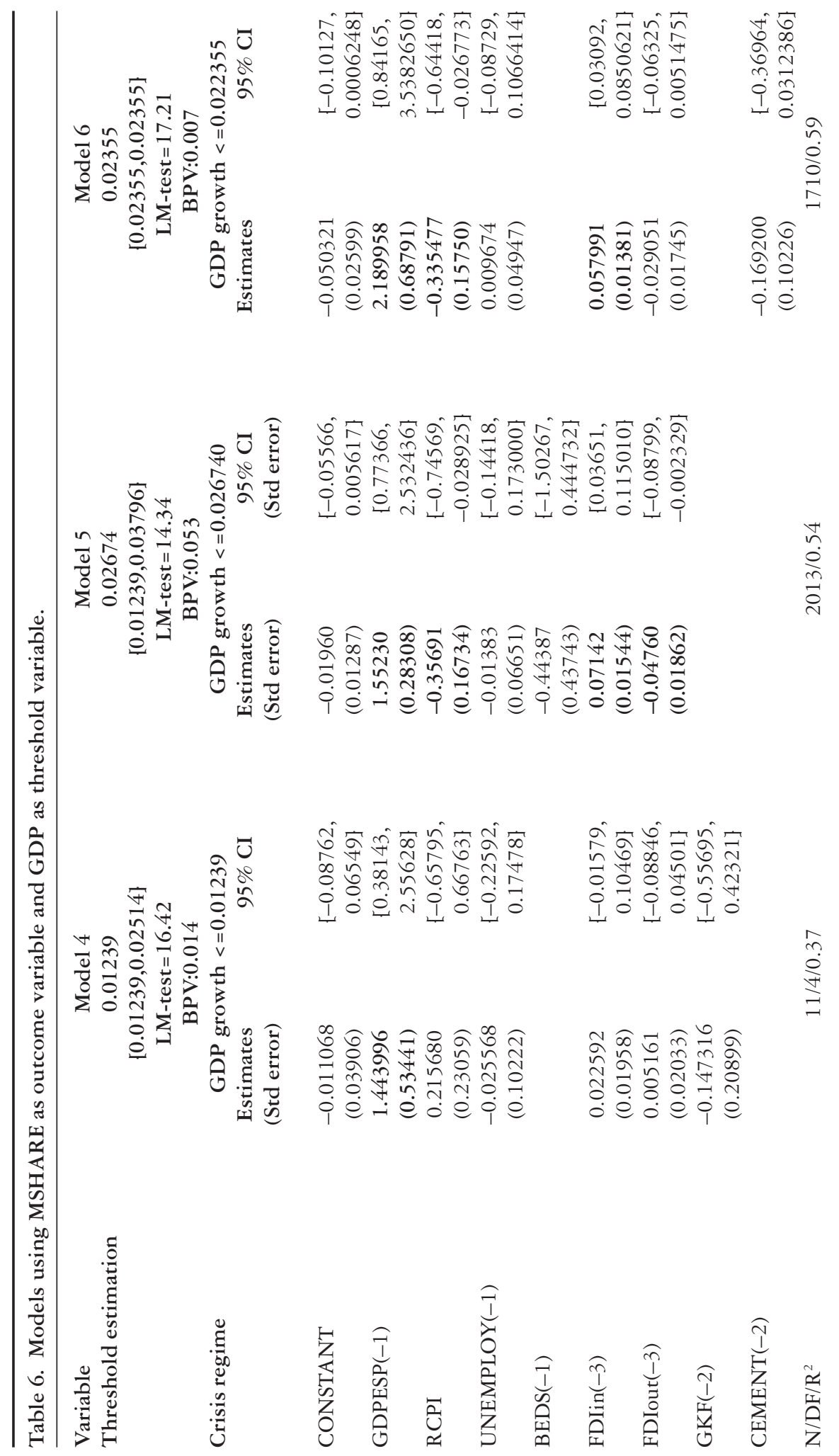




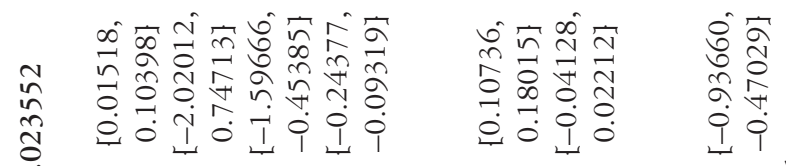

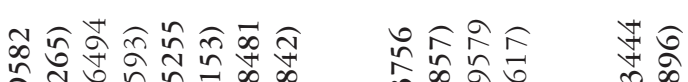

బิतี

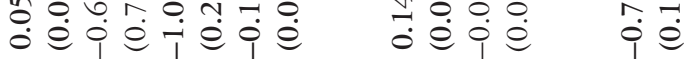

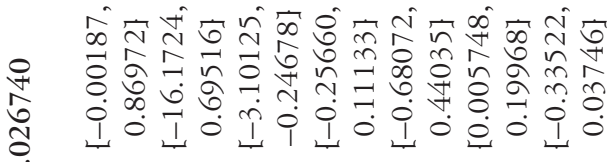

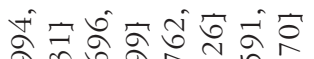

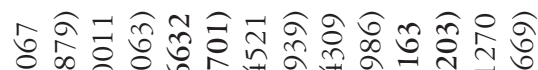

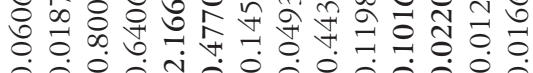

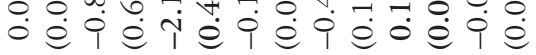

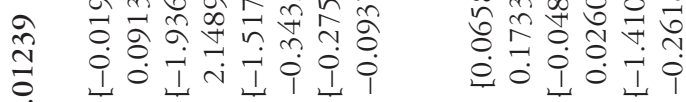

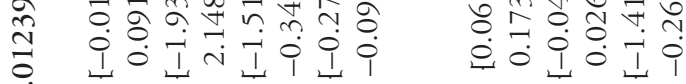

๖ึ்

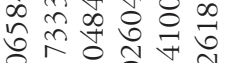

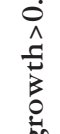

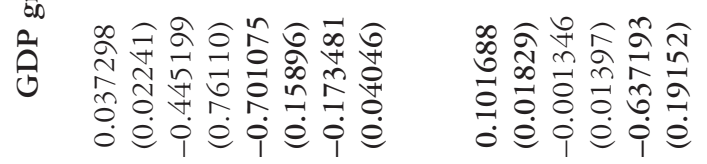

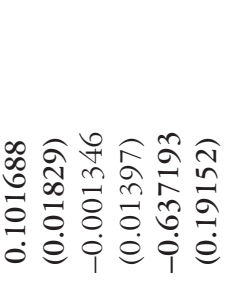

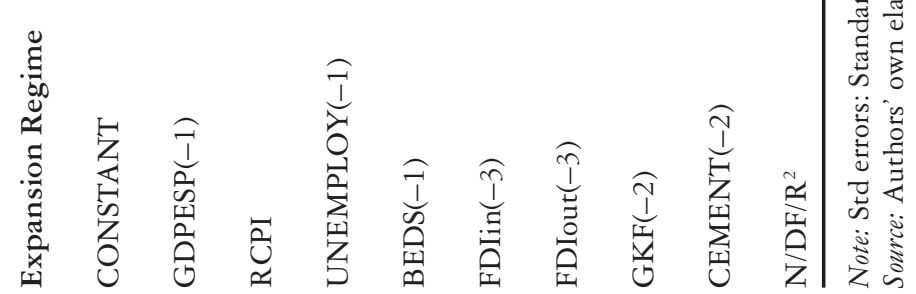


from a GDP growth of $1.23 \%$ (model 4) to $2.67 \%$ (model 5). In other words, when Spanish economic growth is below these values we can consider that Spanish tourism competitiveness is in a crisis regime. The first value is close to the 0.26 percentile and the second is close to the median of the Spanish GDP growth probability distribution.

The bootstrapped $p$-value of the tests in the first row confirms that linearity is rejected for all models, justifying the use of a non-linear approach. The models in Table 6 reflect the expected signs in most of the estimated coefficients and specifically in all of those that reveal statistical significance. GDP growth appears to be positive when associated with market share; price competitiveness appears with a negative sign; inward foreign direct investment has a positive sign, outward foreign direct investment has a negative sign; and unemployment appears with negative sign. Only generic investment GKF and CEMENT and also tourism investment BEDS appear with an unexpected sign in most of the estimations, which could be due to the maturity and saturation levels of the Spanish tourism sector.

The most important finding is that all the models reflect that during the crisis period the growth of GDP is more relevant (bigger and statistically significant coefficients) for tourism competitiveness than in the expansion phase. In fact, in the expansion regime GDP growth lacks statistical significance in all estimated models. This fact confirms the relevance of economic crises for tourism competitiveness.

Conversely, price competitiveness is more determinant (larger and statistically significant coefficients in terms of absolute value) in expansion periods than during times of crisis. With respect to generic investment, a negative sign is obtained for GKF and CEMENT and statistical significance is only achieved during the expansion phase, which reinforces the idea that this is linked to the saturation levels of the destination. If an estimate of the same model was performed for an emerging destination, a different result would probably be obtained for this variable.

Finally, the FDI variable is most relevant in expansion periods, with inward FDI being statistically significant in all estimated models.

Figure 6 shows the evolution of Spain's share of the international tourism market and highlights the crisis periods according to the threshold estimated in model 4 (GDP growth below 1.23\%). Figure 7 displays the same evolution but using the threshold estimated in model 5 (GDP growth below $2.67 \%$ ). The graphs show that the post-Second Oil Crisis in 1979, the early 1990s crisis and the most recent GFC fall into the crisis regime estimated by the models. According to our theory, in all of these periods the evolution of Spain's market share has a downward trend. Conversely, the First Oil Crisis of 1973 is not captured by the model as a crisis period. A plausible explanation for this outcome could be related to the volatility that characterizes the initial period and the difficulties that our estimated model has in accounting for this.

A general interpretation of all of the results obtained is that the dynamics of Spanish tourism competitiveness are influenced by the general variables established by the literature, namely price competitiveness and generic and tourism investment determinants of this competitiveness. However, the crisis periods disrupt the natural functioning of these dynamics provoking disturbances in the determinants of competitiveness that affect the tourism market 


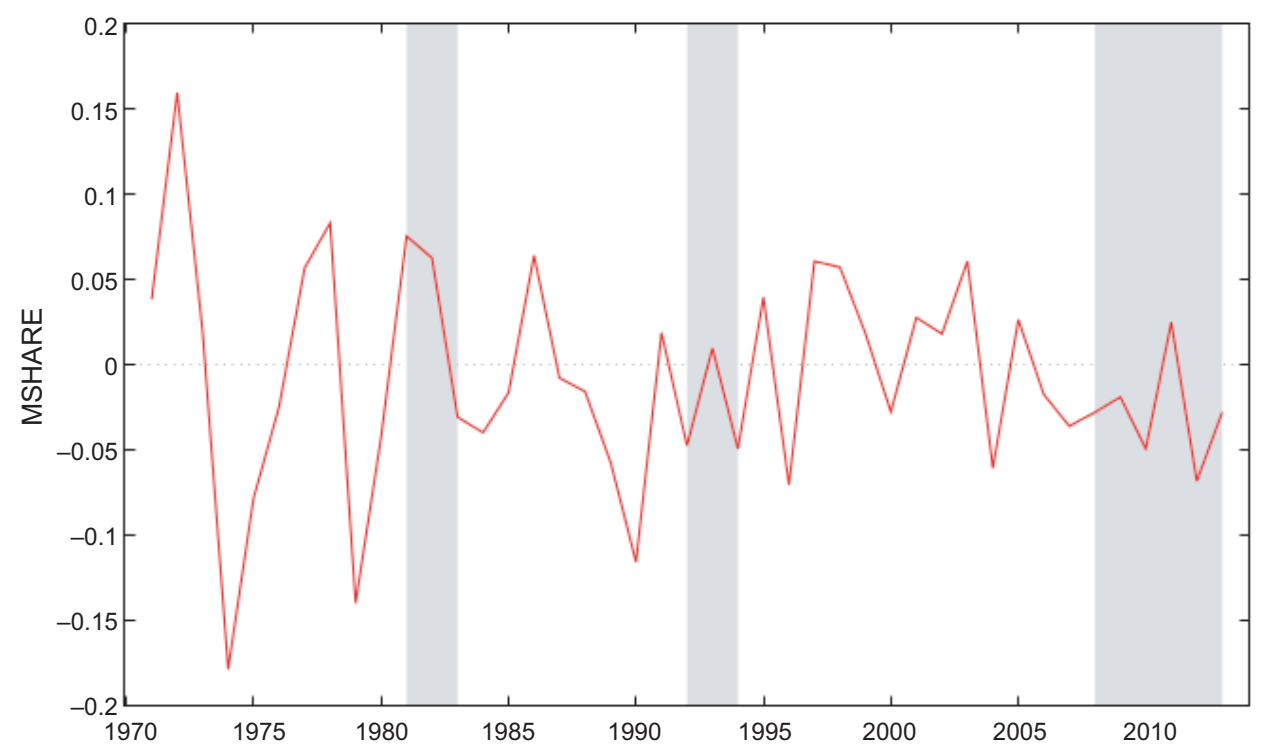

Figure 6. Competitiveness regimes threshold GDP growth 0.01239 . Source: Author's own elaboration.

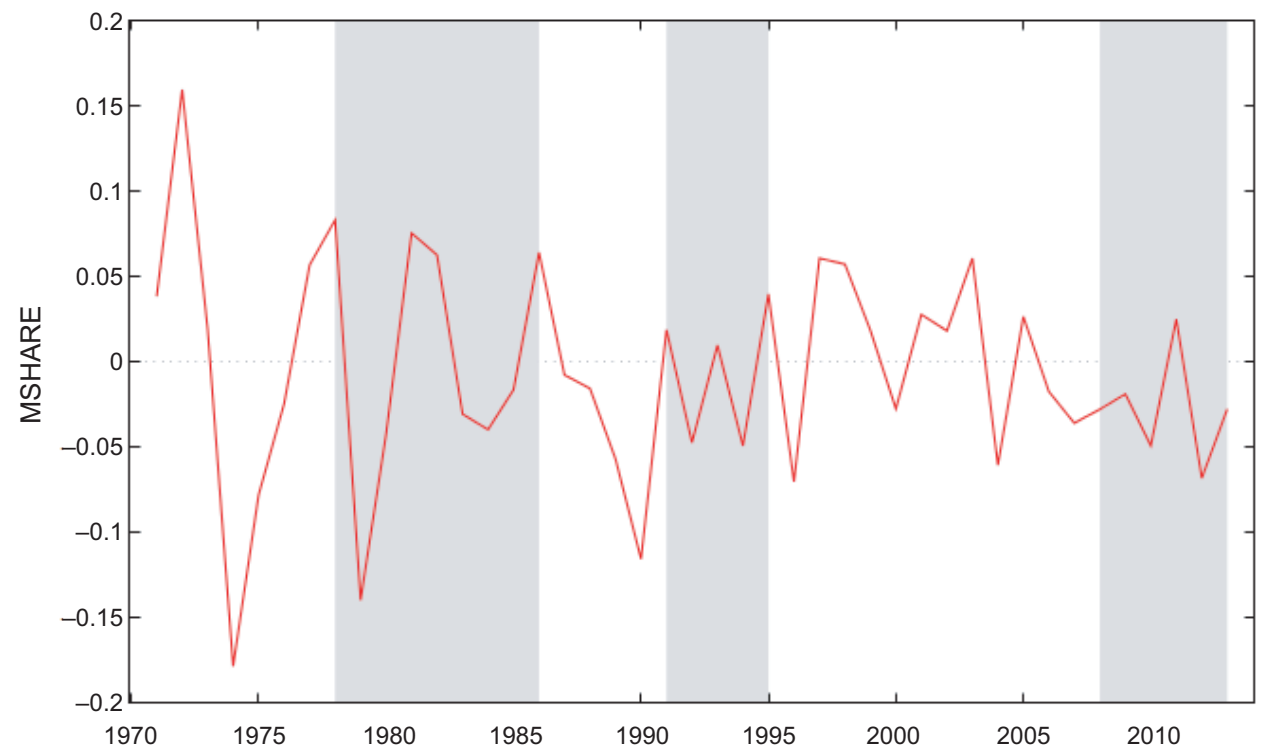

Figure 7. Competitiveness regimes threshold GDP growth 0.02674 . Source: Author's own elaboration.

position of destinations to a greater extent than expected. In our estimations this influence is reflected in a crisis period where the typical mechanism lacks significance and only GDP growth appears to be the most relevant determinant of competitiveness. 


\section{Conclusion}

This study has attempted to take a theoretical approach to competitiveness by proposing, for the first time, a model that establishes the relationships that exist among economic crises, competitiveness and the market success of tourism destinations. In this sense, our article has provided theoretical foundations that could strengthen the empirical research on this topic. The proposed model also introduces some conditions for outcome variance in tourism competitiveness, highlighting the symmetrical or asymmetrical effects that economic crises have on different types of destination.

Although the study of the consequences of crises on tourism is not a new research field, the original aspect of this paper is that it provides an integrated approach framework for understanding some relationships and phenomena which, until now have been only partially addressed in, the literature. In this sense, our holistic model attempts to link previous theoretical and empirical contributions made by different authors, which now appear to be clearly connected. This approach is crucial in a globalized economic context, in which tourism competitiveness is an increasingly important issue.

A key question with this approach is related to the temporary or permanent effects of economic crises on tourism competitiveness and market performance. Although many studies have shown transitory effects of these shocks on tourism demand and have highlighted the resilience of the tourism sector, the proposed model might explicitly recognize the possibility of structural consequences and long-term implications of economic crises by proposing the potential mechanism that causes them. Thus, the model shows that losses in market positions during crises would be irreversible during periods of growth.

The empirical analysis performed confirms that the proposed model is not merely a theoretical or conceptual exercise. Applied to the Spanish case, the model explains the different behaviour of the competitiveness dynamics between crisis and expansion periods. The estimations of several threshold models concludes that not only crises (negative rates of GDP growth), but periods of low growth (up to $2 \%$ in the Spanish case) could be problematic for the competitiveness of tourism destinations.

Therefore, our study could have significant policy relevance because the proposed transmission mechanism operating in this context should indicate potential policy measures to neutralize the negative effects that economic crises can have on destination performance. Similarly, the mechanism could contribute by generating new measures to enable rapid recovery after crisis episodes.

The main limitation of this study is that it is only focused on economic crises and economic determinants of competitiveness. Therefore, in empirical research, it could be difficult to isolate these effects from others (wars, political turmoil, and so on) that can affect tourism destinations. For future research, an empirical application of this model to a broader set of tourism destinations could offer further valuable insight, especially with regard to the symmetrical or asymmetrical character of economic crises in destinations. The increasing recurrence of economic crises and their potential effects on destinations around the world, as well as the significant relevance of the tourism industry in promoting the development of many countries, might justify further efforts to research, improve and debate the proposed model. 


\section{Endnote}

1. http://www.nber.org/cycles/recessions.html.

\section{References}

Alonso, M., and Bremser, K. (2013), 'Strategic responses of the Spanish hospitality sector to the financial crisis', International Journal of Hospitality Management, Vol 32, pp 141-148.

Beaman, J., Huan, T., and Kozak, M. (2001), 'Estimating a Markov Model that incorporates first visit decisions and varying repeat frequency', Tourism Analysis, Vol 6, No 2, pp 81-97.

Bhattacharya, M., and Narayan, P. (2005), 'Testing for the random walk hypothesis in the case of visitors arrivals: evidence form Indian tourism', Applied Economics, Vol 37, No 13, pp 1485-1490.

Butler, R. (1980), 'The concept of tourist area cycle of evolution: implications for management of resources', Canadian Geographer, Vol XXIV, No 1, pp 5-12.

Buisán, A. (1997), 'Exportaciones de turismo y competitividad', Revista de Economía Aplicada, Vol 13, No V, pp 65-81.

Chan, K.S. (1993), 'Consistency and limiting distribution of the least-squares estimator of a threshold autoregressive model', Annals of Statistics, Vol 21, No 1, pp 520-533.

Chia-Lin, C., Thanchanok, K., and McAleer, M. (2012), 'IV estimation of a panel threshold model of tourism specialization and economic development', Tourism Economics: the Business and Finance of Tourism Recreation, Vol 18, No 1, pp 5-41.

Cracolici, M.F., Nijkamp, P., and Rietveld, P. (2006), 'Assessment of tourist competitiveness by analysing destination efficiency', Timbergen Institute Discussion Paper, TI 2006-097/2.

Craigwell, R. (2007), 'Tourism competitiveness in small island developing states', United Nations University - World Institute for Development Economics Research, Research Paper No 2007/ 19.

Craigwell, R., Worrell, D., and Smith, S. (2006), 'The competitiveness of selected Caribbean tourism markets', paper presented at the 2006 Annual Review Seminar of the Central Bank of Barbados, Bridgetown.

Croes, R. (2011), 'Measuring and explaining competitiveness in the context of small island destinations', Journal of Travel Research, Vol 50, No 4, pp 431-442.

Crouch, G. (1995), 'A meta-analysis of tourism demand', Annals of Tourism Research, Vol 22, No 1, pp 103-118.

Crouch, G.I., and Ritchie, J.R. (1999), 'Tourism, competitiveness, and social prosperity', Journal of Business Research, Vol 44, pp 137-152.

d'Hauteserre, A.M. (2000), 'Lesson in managed destination competitiveness: the case of Foxwoods Casino Resort', Tourism Management, Vol 21, pp 23-32.

Divisekera, S. (2003), 'A model of demand for international tourism', Annals of Tourism Research, Vol 30, No 1, pp 31-49.

Durbarry, R., and Sinclair, T. (2003), 'Market share analysis: the case of French tourism demand', Annals of Tourism Research, Vol 30, No 4, pp 927-941.

Dwyer, L. (2001), Destination Competitiveness: Development of a model with application to Australia and the Republic of Korea, Department of Industry Science and Resources, Canberra.

Dwyer, L., and Forsyth, P. (1994), 'Foreign tourism investment: motivation and impact', Annals of Tourism Research, Vol 21, No 3, pp 512-537.

Dwyer, L., and Kim, C. (2003), 'Destination competitiveness: determinants and indicators', Current Issues in Tourism, Vol 6, No 5, pp 369-414.

Dwyer, L., Forsyth, P., and Rao, P. (2000), 'The price competitiveness of travel and tourism: a comparison of 19 destinations', Tourism Management, Vol 21, No 1, pp 9-22.

Dwyer, L., Forsyth, P., and Dwyer, W. (2010), Tourism Economics and Policy, Channel View, Bristol.

Endo, K. (2006), 'Foreign direct investment in tourism-flows and volumes', Tourism Management, Vol 27, pp 600-614.

Enright, M.J., and Newton, J. (2004), 'Tourism destination competitiveness: a quantitative approach', Tourism Management, Vol 26, No 6, pp 777-788.

Enright, M.J., and Newton J. (2005), 'Determinants of tourism destination competitiveness in Asia Pacific: comprehensiveness and universality', Journal of Travel Research, Vol 43, pp 339-350.

Fernando, E. (2010), 'Identifying and predicting turning points in Australian inbound tourism demand growth', $\mathrm{PhD}$ thesis, Victoria University.

Fontagné, L., and Pajot, M. (1997), 'How foreign direct investment affects international trade and 
competitiveness: an empirical assessment', Centre d' Etudes Prospectives et d'Information Internationales, Working Paper No 1997-17 December.

Frechtling, D.C. (1982), 'Tourism trends and the business cycle: tourism in recession', Tourism Management, Vol 3, No 4, pp 285-290.

González, P., and Moral, P. (1996), 'Analysis of tourism trends in Spain', Annals of Tourism Research, Vol 23, pp 739-754.

Gooroochurn, N., and Sugiyarto, G. (2005), 'Competitiveness indicators in the travel and tourism industry', Tourism Economics, Vol 11, No 1, pp 25-43.

Hansen, B. (2000), 'Sample splitting and threshold estimation', Econometrica, Vol 68, pp 575-603.

Hassan, S.S. (2000), 'Determinants of market competitiveness in an environmentally sustainable tourism industry', Journal of Travel Research, Vol 38, pp 239-245.

Heath, E. (2003), 'Towards a model to enhance destination competitiveness: a Southern African perspective', Journal of Hospitality and Tourism Management, Vol 10, No 2, pp 124-141.

Henderson, J.C. (1999), 'Southeast Asian tourism and the financial crisis: Indonesia and Thailand Compared', Current Issues in Tourism, Vol 2, No 4, pp 294-303.

Hill, H., and Jongwanich, J. (2009), Outward foreign direct investment and the financial crisis in developing East Asia', Asian Development Review, Vol 26, No 2, pp 1-25.

Kozak, M., and Rimmington, M. (1999), 'Measuring tourist destination competitiveness: conceptual considerations and empirical findings', Hospitality Management, Vol 18, pp 273-283.

Kun-Huang, H., Hui-Kuang, T., and Solé-Parellada, F. (2011), 'An innovative regime switching model to forecast Taiwan tourism demand', Services Industries Journal, Vol 31, No 10, pp 1603-1612.

Levi-Yeyati, E. Panizza, U., and Stein, E. (2003), 'The cyclical nature of North-South FDI flows', Interamerican Development Bank Working Paper No 479.

Li, G., Song, H., and Witt, S.F. (2005), 'Recent developments in econometric modelling and forecasting', Journal of Travel Research, Vol 44, No 1, pp 82-99.

Lim, C. (1997), 'Review of international tourism demand models', Annals of Tourism Research, Vol 24, No 4, pp 835-849.

Mazanec, J.A., Wöber, K., and Zins, A.H. (2007), 'Tourism destination competitiveness: from definition to explanation?', Journal of Travel Research, Vol 46, pp 86-96.

Ming-Hsiang, C. (2014), 'Asymmetric effects of monetary policy changes on hospitality stock performance', Tourism Economics, Vol 20, No 3, pp 545-566.

Moore, W., and Whitehall, P. (2005), 'The tourism area lifecycle and regime switching models', Annals of Tourism Research, Vol 32, No 1, pp 112-126.

Narayan, P. (2011), 'Are shocks to tourism transitory at business cycle horizons?', Applied Economics, Vol 43, No 16, pp 2071-2077.

Okumus, F., and Karamustafa, K. (2005), 'Impact of an economic crisis: evidence from Turkey', Annals of Tourism Research, Vol 32, No 4, pp 942-961.

Okumus, F., Altinay, M., and Arasli, H. (2005), 'The impact of Turkey's economic crisis of February 2001 on the tourism industry in Northern Cyprus', Tourism Management, Vol 26, pp 95-104.

Omerzel, D., and Mihalic, T. (2008), 'Destination competitiveness - applying different models, the case of Slovenia', Tourism Management, Vol 29, pp 294-307.

Papatheodorou, A. (2004), 'Exploring the evolution of tourism resorts', Annals of Tourism Research, Vol 31, No 1, pp 219-237.

Papatheodorou, A., Roselló, J., and Honggen, X. (2010), 'Global economic crisis and tourism: consequences and perspectives', Journal of Travel Research, Vol 49, No 1, pp 39-45.

Patsouratis, V., Frangouli, Z., and Anastasopoulos, G. (2005), 'Competition in tourism among the Mediterranean countries', Applied Economics, Vol 37, pp 1865-1870.

Pedreño, A., Hidalgo, M., Ayela, R., and Dénia, A. (1990), Libro Blanco del Turismo en la Costa Blanca, Cámara Oficial de Comercio, Industria y Navegación de Alicante, Alicante.

Perles, J., and Ramón, A. (2013a), 'Economic cycles, asymmetric crises and tourism competitiveness: emerging versus mature destinations', Economics Bulletin, Vol 33, No 3, pp 2080-2097.

Perles, J., and Ramón, A. (2013b), 'From economic crises to tourism competitiveness', paper presented at the Conference Celebrating and Enhancing the Tourism Knowledge-based Platform: A Tribute to Jafar Jafari, Palma Mallorca, 23-25 October 2013.

Perles, J., Ramón, A., and Sevilla, M. (2011), 'Determinants of the competitive advantage of residential tourism destinations in Spain', Tourism Economics, Vol 17, No 2, pp 373-403.

Perles, J., Ramón, A., Rubia, A., and Moreno, L. (2013), 'Economic crisis and tourism competitiveness in Spain: permanent effects or transitory shocks?', Current Issues in Tourism (http://dx. doi.org/10.1080/13683500.2013.849666). 
Perles, J., Ramón, A., and Sevilla, M. (2014), 'La cuota de mercado como indicador de competitividad en los destinos turísticos: sentido y limitaciones', Cuadernos de Turismo, Vol 34, pp 265-285.

Porter, M. (1991), La Ventaja Competitiva de las Naciones, Plaza y Janés.

Prideaux, B. (1999), 'Tourism perspectives of the Asian financial crisis: lesson for the future', Current Issues in Tourism, Vol 2, pp 279-293.

Ramón, A. (2002), 'Determining factors in entry choice for international expansion: the case of the Spanish hotel industry', Tourism Management, Vol 23, pp 597-607.

R Core Team (2014), 'R: A language and environment for statistical computing', R Foundation for Statistical Computing, Vienna (http://www.R-project.org/).

Ritchie, J.R., Amaya, C., and Frechling, D. (2010), 'Impacts of the world recession and economic crisis on tourism: North America', Journal of Travel Research, Vol 49, No 1, pp 5-15.

Sanuy, F. (1983), 'El turismo y la crisis económica', Estudios Turísticos, Vol 80, pp 67-76.

Schulmeister, S. (1979), Tourism and the business cycle: econometric models for the purpose of analysis and forecasting of short-term changes in the demand for tourism', Austrian Institute for Economic Research.

Sheldon, P., and Dwyer, L. (2010), 'The global financial crisis and tourism: perspectives of the academy', Journal of Travel Research, Vol 49, No 1, pp 3-4.

Smeral, E. (2010), 'Impacts of the world recession and economic crisis on tourism: forecasts and potential risks', Journal of Travel Research, Vol 49, No 1, pp 31-38.

Smeral, E., and Weber, A. (2000), 'Forecasting international tourism trends to 2010', Annals of Tourism Research, Vol 27, No 4, pp 982-1006.

Smeral, E., and Witt, S.F. (1996), 'Econometric forecasts of tourism demand to 2005', Annals of Tourism Research, Vol 23, No 4, pp 891-907.

Song, H., and Li, G. (2008), 'Tourism demand modelling and forecasting - a review of recent research', Tourism Management, Vol 29, pp 203-220.

Song, H., and Shanshan, L. (2010), 'Impacts of the financial and economic crisis on Tourism in Asia', Journal of Travel Research, Vol 49, No 1, pp 16-30.

Song, H., Witt, S.F., and Jensen, T.C. (2003), 'Tourism forecasting: accuracy of alternative econometric models', International Journal of Forecasting, Vol 19, pp 123-141.

Song, H., Lin, S., Witt, S., and Zhang, X. (2011), 'Impact of financial/economic crisis on demand for hotel rooms in Hong Kong', Tourism Management, Vol 32, pp 172-186.

Song, H., Dwyer L., and Zheng, C. (2012) 'Tourism economics research: a review and assessment', Annals of Tourism Research, Vol 39, No 3, pp 1653-1682.

Stern, M. (1993), 'Global financing in the global marketplace', papers of the First International Conference on Investments and Financing in the Tourism Industry, Jerusalem, Israel, May 1993 , pp 303-307.

Taplin, J. (2003) 'Modelling the choice of second and subsequent trip destinations as a Markov process: behavioural implications', International Congress on Modelling and Simulation, Townsville, Australia.

Teräsvita, T., Tjøstheim, D., and Granger, C. (2010), Modelling Nonlinear Economic Time Series. Advanced Text in Econometric, Oxford University Press, New York.

United Nations Conference on Trade and Development (UNCTAD) (2009), 'Assessing the impact of the current financial and economic crisis on global FDI flows', report of United Nations Conference on Trade and Development, Division on Investment and Enterprise, April.

Uysal, M., Barrett, R., and Marsinko, A. (1995), 'An examination of trip type switching and market share: Markov chain model application', Journal of Travel and Tourism Marketing, Vol 4, No 1, pp 45-56.

Vanhove, N. (2011), The Economics of Tourism Destinations, Elsevier, Amsterdam.

White, K.J. (1985), 'An international travel demand model US travel to western Europe', Annals of Tourism Research, Vol 12, pp 529-545.

Witt, S., and Witt, C. (1995), 'Forecasting tourism demand: a review of empirical research', International Journal of Forecasting, Vol 11, pp 447-475.

World Economic Forum (2013), 'The travel and tourism competitiveness report 2013: reducing barriers to economic growth and job growth', Geneva.

Zhang, J., and Jensen, C. (2007), 'Comparative advantage: explaining tourism flows', Annals of Tourism Research, Vol 34, No 1, pp 223-243. 